\title{
JTC-801 inhibits the proliferation and metastasis of the Hep G2 hepatoblastoma cell line by regulating the phosphatidylinositol 3-kinase/protein kinase B signalling pathway
}

\author{
BUFEI $\mathrm{ZHAO}^{1 *}$ and TING $\mathrm{HU}^{2 *}$ \\ ${ }^{1}$ Department of Hepatopancreatobiliary Surgery, Affiliated Hospital of Beihua University, Jilin 132001; \\ ${ }^{2}$ Department of Oncology, The First Affiliated Hospital of Changchun University of Chinese Medicine, \\ Changchun, Jilin 130021, P.R. China
}

Received January 29, 2018; Accepted September 17, 2018

DOI: $10.3892 / \mathrm{ol} .2018 .9780$

\begin{abstract}
The increased worldwide mortality rate due to liver cancer may be attributed to the aggressive nature of the disease. Signal transduction through G-protein-coupled receptors (GPCRs) can affect a number of aspects of cancer biology, including invasion, migration and vascular remodelling. JTC-801, a novel GPCR antagonist, has demonstrated promising anticancer effects in adenocarcinoma and osteosarcoma cells. In the present study, the effect of JTC-801 on the proliferation and migration of hepatoblastoma Hep G2 cells was investigated. The Cell Counting Kit- 8 assay revealed that JTC-801 markedly suppressed the growth of the Hep G2 cells. Additionally, JTC-801 significantly inhibited cell invasion and migration in a Transwell assay. Furthermore, the expression of anti-apoptotic protein B-cell lymphoma 2 decreased and the expression of the pro-apoptotic proteins active caspase-3 and apoptosis regulator BAX increased in the Hep G2 cells following JTC-801 treatment. Additionally, JTC-801 suppressed the phosphatidylinositol 3-kinase (PI3K)/protein kinase B (AKT) signalling pathway in the Hep G2 cells. Therefore, the present study revealed that JTC-801 can induce
\end{abstract}

Correspondence to: Dr Bufei Zhao, Department of Hepatopancreatobiliary Surgery, Affiliated Hospital of Beihua University, 12 Jie-Fang-Zhong Road, Jilin 132001, P.R. China

E-mail: zhaobufeidr@163.com

*Contributed equally

Abbreviations: GPCRs, G-protein-coupled receptors; PI3K, phosphatidylinositol 3-kinase; AKT, protein kinase B; mTOR, mechanistic target of rapamycin; Bcl-2, B-cell lymphoma 2; Bax, apoptosis regulator BAX; P70S6K, P70S6 kinase; CCK-8, Cell Counting Kit-8; FITC, fluorescein isothiocyanate; PI, propidium iodide

Key words: JTC-801, liver cancer, Hep G2 cell line, proliferation, invasion, migration, apoptosis, phosphatidylinositol 3-kinase/protein kinase B the apoptosis of Hep $\mathrm{G} 2$ cells by regulating the PI3K/AKT signalling pathway, which suggests that JTC-801 may be a potential novel drug target for clinical liver cancer treatment.

\section{Introduction}

The increased global mortality rate due to liver cancer may be attributed to the aggressive nature of the disease (1). Liver cancer accounts for $>1$ million newly diagnosed cases annually, making it a global health care problem with increasing incidence (2). The incidence of liver cancer is markedly high in developing countries and is steadily rising in developed countries (3). Although there is a continuous rise in the 5-year survival rates for liver and intrahepatic bile duct cancer, the numbers of new cases and estimated mortalities are increasing $(4,5)$. Liver cancer is often not detectable until late in disease progression (6), and chemotherapy remains the primary treatment for numerous patients with cancer of advanced stage. However, chemotherapy has side effects, particularly in normal tissues with potent proliferative activity (7), and this therapy does not always lead to a better prognosis. Therefore, finding novel therapeutic entities against longer cancer cell survival and growth is required.

JTC-801 [N-(4-amino-2-methylquinolin-6-yl)-2-(4ethylphenoxymethyl)benzamide monohydrochloride] is a high-affinity and selective opioid receptor-like 1 (ORL1) receptor antagonist, which belongs to the family of G-protein-coupled receptors (GPCRs) (8). Studies have demonstrated that signal transduction through GPCRs can affect numerous aspects of cancer biology, including invasion, migration and vascular remodelling $(9,10)$. Furthermore, ORL1 may antagonize lipopolysaccharide-stimulated proliferation, migration and inflammatory signalling in human glioblastoma U87 cells (11). In a screening of agents that interact with GPCR pathways, Song et al (12) revealed that JTC-801 induces pH-dependent cell death (alkaliptosis) specifically in cancer cells, including pancreatic ductal adenocarcinoma cells, by reducing the expression of carbohydrate antigen 9 , which is increased in human cancer tissues. JTC-801 may be used in the development of treatment for pancreatic cancer. Zheng et al (13) described the antitumour effects of JTC-801 
on human osteosarcoma cells. Therefore, JTC-801 may be used for the treatment of other cancer types, including liver cancer.

In the present study, the effect of JTC-801 on the Hep G2 hepatoblastoma cell line was investigated. First, the Cell Counting Kit-8 (CCK-8) assay was used to detect the proliferation of Hep G2 cells treated with JTC-801. As cancer is characterized by increased migratory/invasive capacity, the migratory and invasive abilities of Hep G2 cells following JTC-801 treatment were investigated. Furthermore, the expression of apoptotic proteins was assayed in the Hep G2 cells following JTC-801 treatment. Additionally, the phosphatidylinositol 3-kinase (PI3K)/protein kinase B (AKT) signalling pathway may have a function in inducing the apoptosis of Hep G2 cells.

\section{Materials and methods}

Cell lines and cell culture. The human Hep G2 cell line was purchased from the Shanghai Cell Bank (Shanghai Institute for Biological Science, Chinese Academy of Science, Shanghai, China). Cells were cultured in RPMI-1640 medium (GE Healthcare Lifesciences, Logan, UT, USA) supplemented with $10 \%$ fetal bovine serum (FBS; Gibco; Thermo Fisher Scientific, Inc., Waltham, MA, USA), $100 \mathrm{U} / \mathrm{ml}$ penicillin and $0.1 \mathrm{mg} / \mathrm{ml}$ streptomycin (both Sigma-Aldrich; Merck KGaA, Darmstadt, Germany) at $37^{\circ} \mathrm{C}$ in an incubator with $5 \% \mathrm{CO}_{2}$. When the cells entered the logarithmic growth phase they were washed 3 times with PBS and digested with $0.25 \%$ trypsin/EDTA (Beijing Solarbio Science \& Technology Co., Ltd., Beijing, China). Cells were resuspended in RPMI-1640 medium containing $10 \%$ FBS to form a single-cell suspension. The cells were seeded in a 6-well plate for subsequent experiments. When the cell density reached $\sim 80 \%$, the cells were treated with $20 \mu \mathrm{M}$ JTC-801 (MedChem Express, Monmouth Junction, NJ, USA), whereas the negative control group was treated with $0.1 \%$ dimethylsulfoxide (DMSO) (Amresco, LLC, Solon, OH, USA), for $24 \mathrm{~h}$ at room temperature.

Western blot analysis. Following the treatment of the cells with DMSO and JTC-801 for $24 \mathrm{~h}$, protein was extracted with radioimmunoprecipitation assay lysis buffer with the protease inhibitor phenylmethylsulfonyl fluoride (CWBio, Beijing, China). The concentration was determined using the BCA method (CWBio). The protein was heated at $95^{\circ} \mathrm{C}$ for $5 \mathrm{~min}$. Overall, $\sim 20 \mu \mathrm{g}$ protein per group was added to each well in the vertical electrophoresis tank, separated by $10 \%$ SDS-PAGE and transferred onto a polyvinylidene fluoride membrane. The membrane was blocked with 5\% non-fat milk in Tris-buffered saline containing $0.1 \%$ Tween-20 (TBST; Beijing Solarbio Science \& Technology Co., Ltd.) for $1 \mathrm{~h}$ at room temperature and incubated with primary antibodies at $4^{\circ} \mathrm{C}$ overnight. On the second day, the membrane was washed 3 times in TBST for $5 \mathrm{~min}$ and incubated with secondary antibodies at room temperature for $1 \mathrm{~h}$. An enhanced chemiluminescence chromogenic substrate (ProteinTech Group, Inc., Chicago, IL, USA) was added to visualize the bands, following the washing of the membrane. The grey value was scanned by Quantity One software (version 4.6.9; Bio-Rad Laboratories, Inc., Hercules, CA, USA). $\beta$-tubulin served as the internal control. The relative expression of each protein was calculated against that of $\beta$-tubulin. Western blotting was performed with the following antibodies: Rabbit anti-human AKT (cat. no. 4691; 1:1,000 dilution), rabbit anti-human p-AKT (cat. no. 4060; 1:1,000 dilution), rabbit anti-human mechanistic target of rapamycin (mTOR; cat. no. 2983; 1:1,000 dilution), rabbit anti-human p-mTOR (cat. no. 2971; 1:1,000 dilution) (all Cell Signaling Technology, Inc., Danvers, MA, USA), rabbit anti-human B-cell lymphoma 2 (Bcl-2; cat. no. 12789-1-AP; 1:1,000 dilution), rabbit anti-human apoptosis regulator BAX (Bax; cat. no. 50599-2-Ig; 1:1,000 dilution), rabbit anti-human active caspase-3 (cat.no. 19677-1-AP; 1:1,000 dilution), rabbit anti-human cyclin D1 (cat. no. 60186-1-Ig; 1:1,000 dilution), rabbit anti-human p70S6 kinase (p70S6K; cat. no. 14485-1-AP; 1:1,000 dilution), rabbit anti-human tubulin (cat. no. 10068-1-AP; 1:5,000 dilution) and the secondary horseradish peroxidase-labelled goat anti-rabbit/goat anti-mouse antibody (cat. no. 10545-2-AP; 1:5,000 dilution) (all ProteinTech Group, Inc.).

Cell Counting Kit-8 (CCK-8) proliferation test. Hep G2 cells from the conventional culture were digested with $0.25 \%$ trypsin-EDTA solution for $2 \mathrm{~min}$ at room temperature and counted in preparation of the cell suspension. Subsequently, $100 \mu 1$ of the cell suspension was seeded onto a 96-well plate with 1,000 cells per well and $0.1 \%$ DMSO was added to the negative control group, while $0.02,0.2,2,20$ or $200 \mu \mathrm{M}$ JTC-801 was added to the experimental groups. The cells were cultured in a $5 \% \mathrm{CO}_{2}$ incubator at room temperature to detect cell viability once every $24 \mathrm{~h}$. Prior to detection, $10 \mu \mathrm{l} \mathrm{CCK}-8$ solution (CWBio) was added to each well and incubated at $37^{\circ} \mathrm{C}$ for $1.5 \mathrm{~h}$. The optical density (OD) was measured with a microplate reader at $450 \mathrm{~nm}$ and the growth curve was plotted.

Cell invasion and migration assessed by Transwell assay. Matrigel (BD Biosciences, Franklin Lakes, NJ, USA) was dissolved overnight (serum-free RPMI-1640 medium, 1:6 dilution) and $100 \mu \mathrm{l}$ was added to the upper chamber of the 24-well Transwell insert (Merck KGaA). Once the Matrigel was evenly distributed, it was placed into a $\mathrm{CO}_{2}$ incubator and cultivated for $4-6 \mathrm{~h}$ at $37^{\circ} \mathrm{C}$ until gel formation. Subsequent to the culture medium drying, $500 \mu 1$ serum-free medium was added to the bottom of the wells to hydrate the basement membrane for $30 \mathrm{~min}$. The cell suspension, treated with JTC-801 for $24 \mathrm{~h}$ at room temperature, was prepared using serum-free RPMI-1640 medium. A total of $100 \mu \mathrm{l}$ cell suspension $\left(1 \times 10^{5}\right.$ cells) was loaded into the upper chamber and $500 \mu \mathrm{l}$ complete culture medium including $10 \%$ FBS was added to the bottom of the Transwell insert for incubation overnight at room temperature. The following day, the Transwell insert was removed and cells remaining on the upper chamber were removed with a cotton swab. Following the washing of the chamber with PBS, the cells that adhered to the membrane were fixed in $4 \%$ paraformaldehyde for $30 \mathrm{~min}$, stained with $0.1 \%$ crystal violet for $20 \mathrm{~min}$, both at room temperature, and washed with PBS. Finally, 5 visual fields were selected randomly using a BX51 inverted microscope (Olympus Corporation, Tokyo, Japan) at x100 magnification, and images were captured for cell counts.

The migration assay procedure was similar to that of the invasion assay except that Matrigel was not placed in the Transwell chamber and $5 \times 10^{3}$ cells were used. 


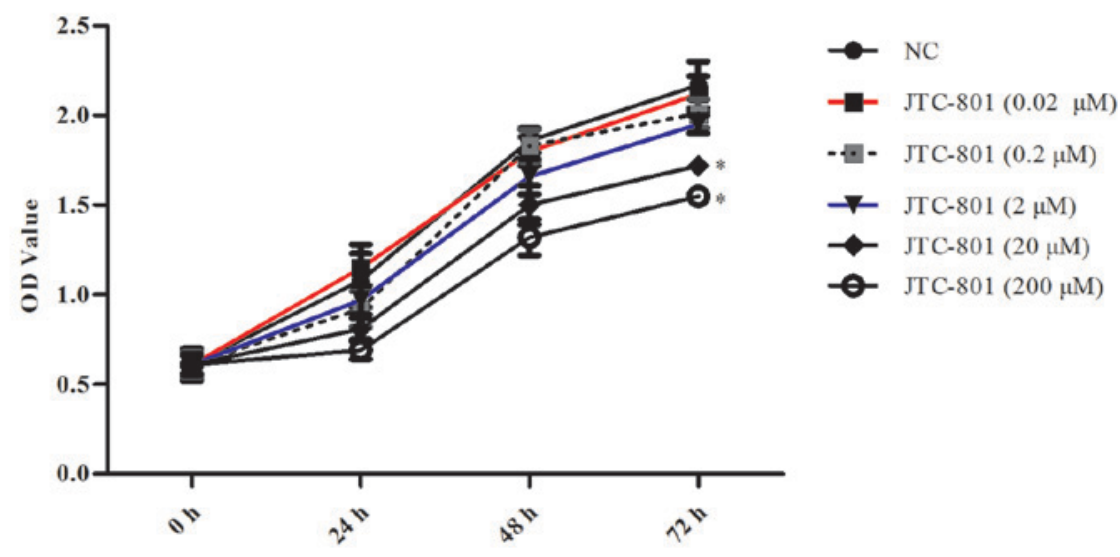

Figure 1. JTC-801 inhibits Hep G2 cell proliferation in the CCK-8 assay. The results indicate that JTC-801 inhibited Hep G2 proliferation in a dose- and time-dependent manner. The relative cell proliferation is plotted following different doses of JTC-801 treatment for 24,48 and $72 \mathrm{~h}$. " $\mathrm{P}<0.05$ compared with the NC group. OD, optical density; NC, negative control.
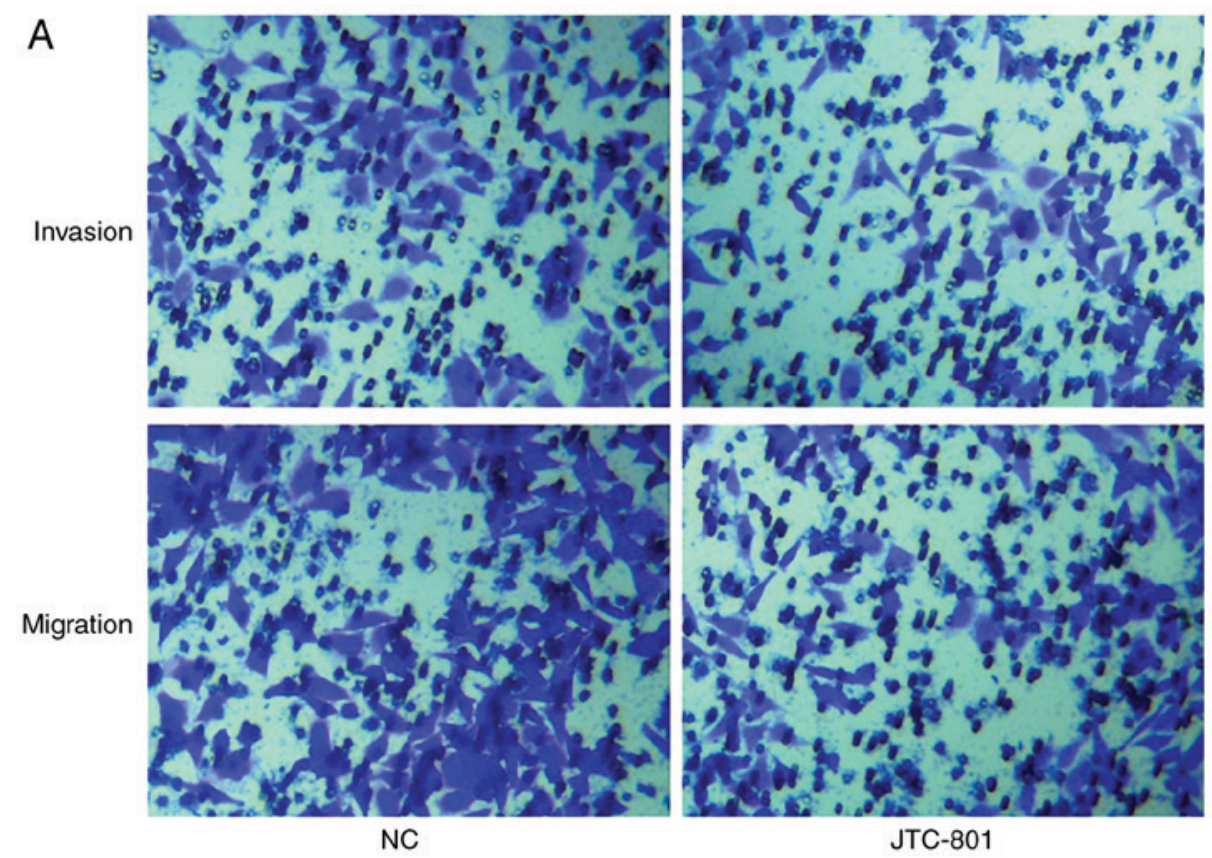

\section{B}

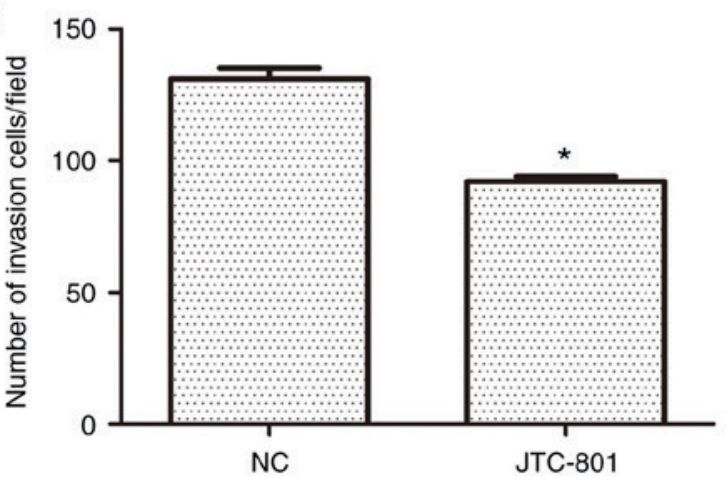

C

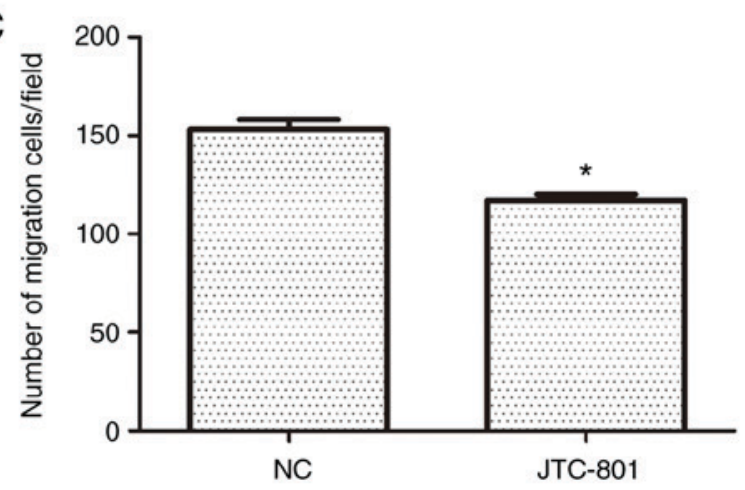

Figure 2. JTC-801 inhibits Hep G2 cell invasion and migration. (A) Representative images of crystal violet-stained invasive and migratory Hep G2 cells. Images were captured using an inverted microscope at x100 magnification. Quantification of (B) invasion and (C) migration. "P<0.05 compared with the NC group. NC, negative control.

Cell apoptosis assay. The Hep G2 cells were treated with JTC-801 for $24 \mathrm{~h}$, as aforementioned, and the medium was removed and replaced with $500 \mu 1$ serum-free medium. Following starvation for $24 \mathrm{~h}$, the cells were harvested, 

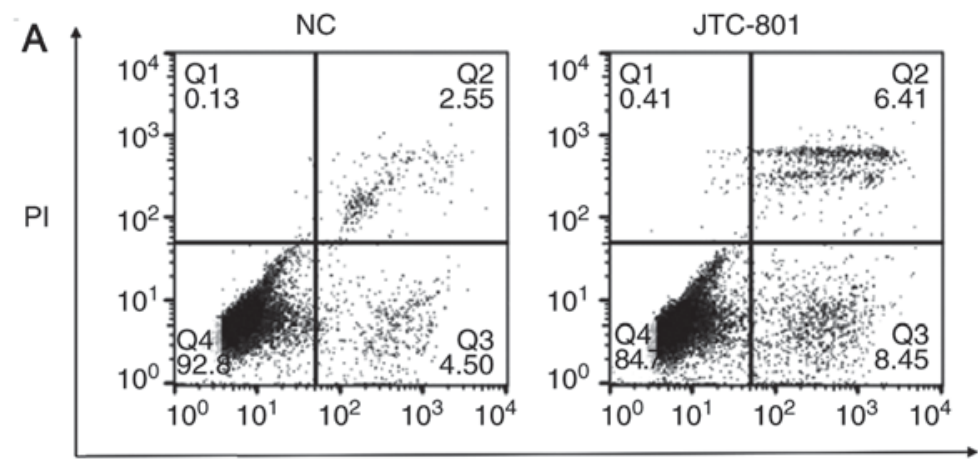

B

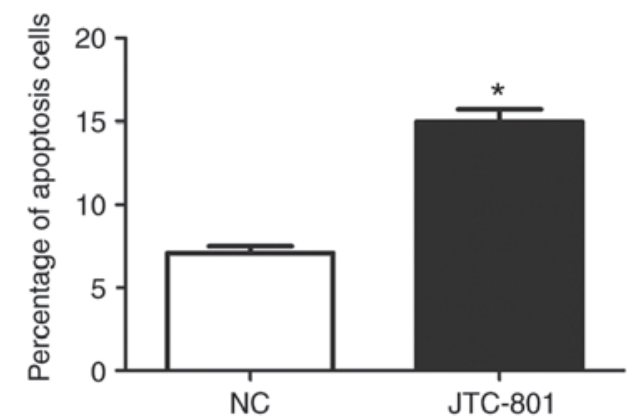

C

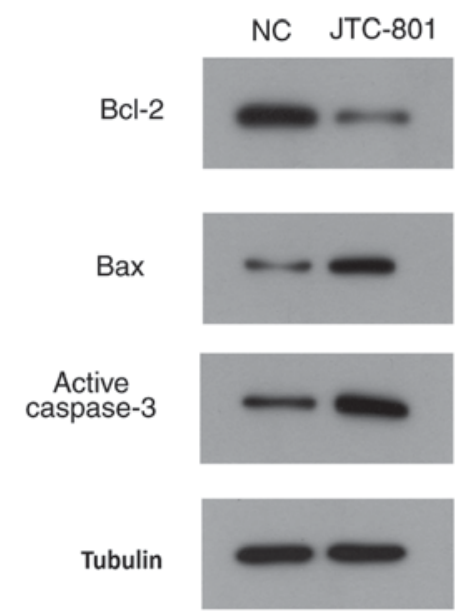

D

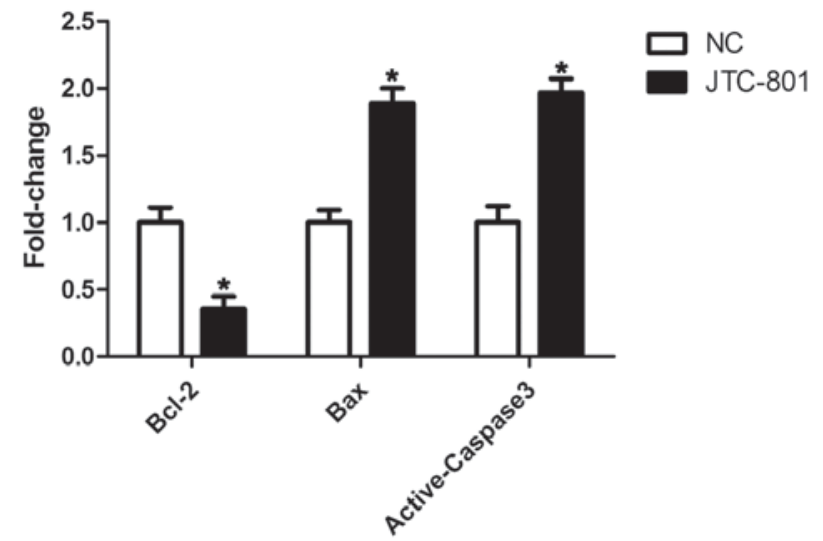

Figure 3. JTC-801 induces Hep G2 cell apoptosis. Hep G2 cells were treated with JTC-801 for 24 h and labelled with Annexin V-FITC and PI, followed by (A) flow cytometric analysis and (B) quantification. (C) Western blot analysis of proteins from Hep G2 cells treated with JTC-801 for 24 h. The band intensities were quantified. The results were normalized to the tubulin loading control. (D) Relative levels of apoptosis-related proteins. * $\mathrm{P}<0.05$ compared with the NC group. NC, negative control; PI, propidium iodide; FITC, fluorescein isothiocyanate; Bcl-2, B-cell lymphoma 2; Bax, apoptosis regulator BAX.

digested with trypsin without EDTA, collected in a centrifuge tube, centrifuged at $200 \mathrm{x} \mathrm{g}$ for $5 \mathrm{~min}$ at room temperature, resuspended in pre-cooled PBS at $4^{\circ} \mathrm{C}$ and centrifuged again as aforementioned, and then the supernatant was carefully aspirated. A total of $200 \mu \mathrm{l}$ Annexin V-FITC binding solution (contained within the kit) was added to resuspend the cells and the cell density was adjusted to $1-5 \times 10^{6}$ cells $/ \mathrm{ml}$. Overall, $\sim 100 \mu \mathrm{l}$ cell suspension was transferred into a 5-ml flow tube following staining with $5 \mu \mathrm{l}$ Annexin V-fluorescein isothiocyanate (FITC) (FXP018-100; 4A Biotech Co., Ltd., Beijing, China) for $5 \mathrm{~min}$ at room temperature and kept in the dark. The cells were stained with $10 \mu \mathrm{l}$ propidium iodide (PI) in $400 \mu \mathrm{l}$ PBS for $10 \mathrm{~min}$ at room temperature and kept in the dark, prior to collection and detection using flow cytometry. The results were analysed with FlowJo software (version 7.6.5; Tree Star, Inc., Ashland, OR, USA).

Statistical analysis. The experimental data were analysed by SPSS statistical analysis software (version 18.0; SPSS Inc., Chicago, IL, USA). The results were expressed as the mean \pm standard deviation. The comparison of 2 groups was performed using the Student's t-test and $>2$ groups were compared using one-way analysis of variance. Multiple comparisons between the groups were performed using a Student-Newman-Keuls test. $\mathrm{P}<0.05$ was considered to indicate a statistically significant difference.

\section{Results}

JTC-801 inhibits Hep G2 cell proliferation. To evaluate the effect of JTC-801 on liver cancer, the Hep G2 cell line was selected and treated with various doses of JTC-801 (0.02, 0.2, 2,20 and $200 \mu \mathrm{M}$ ) for 24,48 and $72 \mathrm{~h}$ to detect cell viability. As presented in Fig. 1, higher concentrations of JTC-801 $(\geq 20 \mu \mathrm{M})$ led to a statistically significant decrease in the proliferation of the Hep G2 cells compared with the control $(\mathrm{P}<0.05)$. In the following experiment, $20 \mu \mathrm{M}$ JTC-801 was used. Furthermore, the OD value decreased significantly $(\mathrm{P}<0.05$; Fig. 1$)$ at $72 \mathrm{~h}$. This suggests that JTC-801 may effectively inhibit liver cancer Hep G2 cell proliferation.

JTC-801 inhibits Hep G2 cell invasion and migration. The effects of JTC-801 on the invasion and migration ability of the Hep G2 cells were investigated using a Transwell assay (Fig. 2A). In the invasion experiment, the number of crystal violet-stained cells was decreased following the JTC-801 treatment. Similarly, in the migration experiment, cell migration was also decreased. These results suggest that JTC-801 may inhibit the metastasis of Hep G2 cells. There were fewer invaded cells in the JTC-801-treated group than in the control group ( $92 \pm 2$ vs. $131 \pm 4$ cells, respectively), indicating a negative effect of JTC-801 on the invasion ability of the Hep G2 cells ( $\mathrm{P}<0.05$; Fig. 2B). The capacity for migration was also 
A

AKT
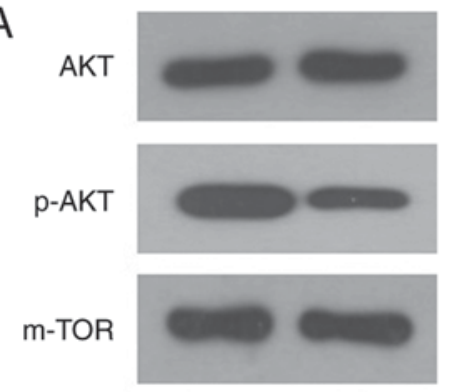

$\left.\begin{array}{ll}B & 1.5 \\ & \end{array}\right]$
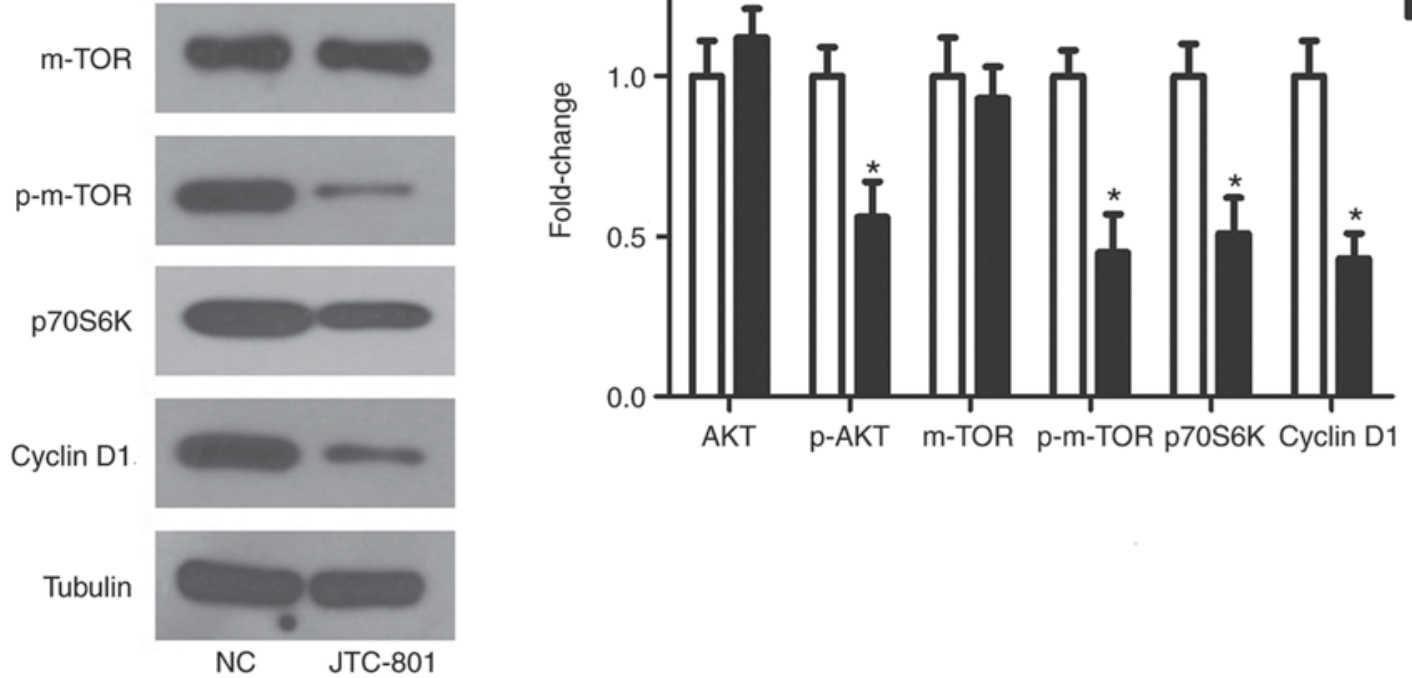

Figure 4. Effects of JTC-801 on the phosphatidylinositol 3-kinase/AKT signalling pathway in Hep G2 cells. (A) Expression levels of AKT, p-AKT, mTOR, p-mTOR, p70S6K and cyclin D1 were measured in the Hep G2 cells treated with JTC-801 using western blot analysis. (B) The relative protein levels of AKT, p-AKT, mTOR, p-mTOR, p70S6K and cyclin D1 compared with the control group. "P<0.05 compared with the NC group. AKT, protein kinase B; p-AKT, phosphorylated AKT; mTOR, mechanistic target of rapamycin; p-mTOR, phosphorylated mTOR; P70S6K, P70S6 kinase; NC, negative control.

inhibited in the JTC-801-treated cells as compared with that in the negative control group ( $117 \pm 3$ vs. $153 \pm 5$ cells, respectively), and the results were significantly different $(\mathrm{P}<0.05$; Fig. $2 \mathrm{C})$.

JTC-801 promotes Hep G2 cell apoptosis. The impact of JTC-801 on Hep G2 cell apoptosis was determined by an Annexin V-FITC and PI double-staining assay. The apoptosis rate in the JTC-801-treated group was $14.86 \%$, while the apoptosis rate in the control group was $7.05 \%$. The statistical analysis suggested that the apoptosis rate in the JTC-801-treated group was significantly increased compared with that in the control group $(\mathrm{P}<0.05$; Fig. 3B). Furthermore, the apoptosis regulators, including anti-apoptotic protein $\mathrm{Bcl}-2$, and pro-apoptotic proteins active caspase- 3 and Bax, were analysed by western blotting (Fig. 3C). In concordance with the flow cytometry analysis, the western blotting revealed that the expression of the anti-apoptotic protein $\mathrm{Bcl}-2$ was decreased, and the expression of the pro-apoptotic proteins active caspase- 3 and Bax was increased in the JTC-801-treated group compared with that in the control group $(\mathrm{P}<0.05 ;$ Fig. $3 \mathrm{D})$. These results indicate that JTC-801 promotes Hep G2 cell apoptosis.

JTC-801 suppresses the PI3K/AKT pathway in Hep G2 cells. The PI3K/AKT signalling pathway is important in tumour progression. Proteins mTOR, p70S6K and cyclin D1 were selected as indicators to evaluate the activity of the PI3K/AKT signalling pathway following the JTC-801 treatment. The results of the western blotting revealed that the phosphorylation levels of AKT and mTOR were significantly decreased in the JTC-801-treated Hep G2 cells, as were the expression levels of p70S6K and cyclin D1 ( $\mathrm{P}<0.05$; Fig. 4). These results suggest that JTC-801-induced Hep G2 cell growth inhibition functions via the PI3K/AKT pathway.

\section{Discussion}

In the present study, the inhibition of hepatoblastoma Hep G2 cell proliferation, invasion and migration by the JTC-801 antagonist was demonstrated, along with the promotion of cell apoptosis. Finally, the effects of JTC-801 on Hep G2 cells were indicated to be associated with the inhibition of PI3K/AKT signalling.

JTC-801 is an opioid analgesic drug used in scientific research. However, the antitumour activity of JTC-801 is not dependent on its known analgesic function (14). JTC-801 contributes to this process by inducing a unique $\mathrm{pH}$-dependent form of regulated cell death known as alkaliptosis $(14,15)$. In U20S osteosarcoma cells, JTC-801 inhibited cell growth by promoting apoptosis via the PI3K/AKT signalling pathway (13). Furthermore, JTC-801 demonstrated its anticancer effect in the ovarian cancer SKOV3 cell line, particularly on cell growth and metastasis (16). Song et al (12) reported that JTC-801 may be used for the treatment of pancreatic cancer. Similarly, the present study revealed the inhibitory effect of the drug on Hep G2 hepatoblastoma cells. The anticancer effect of JTC-801 only occurred at a concentration $\geq 20 \mu \mathrm{M}$. The high concentration of JTC-801 $(>100 \mu \mathrm{M})$ acts on a wide range of receptors, including GPCRs, ion channel receptors and nociception opioid peptide receptors (17). Therefore, the mechanism by 
which JTC-801 functions through receptors requires further experimental validation.

The results of the western blot analysis indicated that JTC-801 may affect the expression of apoptosis-related proteins in liver cancer. Apoptosis is an important antitumour pathway and several antitumour drugs serve an important role in cancer by inducing apoptosis $(18,19)$. The activation of apoptosis is regulated by multiple signalling pathways, of which the PI3K/AKT pathway is one of the most important (20). The PI3K/AKT pathway regulates a number of malignant phenotypes, including anti-apoptotic, cell growth and proliferation phenotypes $(21,22)$. In this pathway, AKT activation inhibits cell cycle arrest and angiogenesis, and promotes tumour invasion and metastasis via phosphorylation of the protein kinase mTOR $(23,24)$. Furthermore, P70S6K, which is closely associated with cell proliferation, is located downstream of the PI3K/AKT/mTOR pathway (25). Cyclin D1 has also been reported to be a direct downstream target of the PI3K/AKT signalling pathway (26). The expression of cyclin D1 is increased in different types of tumour tissues. The present western blot results demonstrated that the phosphorylation levels of AKT and mTOR were decreased significantly in JTC-801-treated Hep G2 cells. Similarly, the expression levels of p70S6K and cyclin D1 were reduced following JTC-801 treatment. These results suggest that JTC-801 may have an antitumour effect via the regulation of apoptosis through the PI3K/AKT pathway.

In summary, the present study demonstrated that JTC-801 inhibited cell proliferation, invasion and migration, and promoted cell apoptosis through the PI3K/AKT signalling pathway in hepatoblastoma Hep G2 cells. This study provides a basis for further clinical research on JTC-801 in liver cancer treatment.

\section{Acknowledgements}

Not applicable.

\section{Funding}

No funding was received.

\section{Availability of data and materials}

The datasets analysed during the present study are available from the corresponding author on reasonable request.

\section{Authors' contributions}

BFZ designed the study and was involved in data collection. $\mathrm{TH}$ analysed and interpreted the experimental data. Both authors prepared figures, wrote the initial manuscript and approved the final manuscript.

\section{Ethics approval and consent to participate}

Not applicable.

\section{Patient consent for publication}

Not applicable.

\section{Competing interests}

The authors declare that they have no competing interests.

\section{References}

1. Pang Y, Kartsonaki C, Turnbull I, Guo Y, Clarke R, Chen Y, Bragg F, Yang L, Bian Z, Millwood IY, et al: Diabetes, plasma glucose and incidence of fatty liver, cirrhosis and liver cancer: A prospective study of 0.5 million people. Hepatology 68 : 1308-1318, 2018

2. Lozano R, Naghavi M, Foreman K, Lim S, Shibuya K, Aboyans V, Abraham J, Adair T, Aggarwal R, Ahn SY, et al: Global and regional mortality from 235 causes of death for 20 age groups in 1990 and 2010: A systematic analysis for the Global Burden of Disease Study 2010. Lancet 380: 2095-2128, 2012.

3. Costentin CE, Layese R, Bourcier V, Cagnot C, Marcellin P, Guyader D, Pol S, Larrey D, De Lédinghen V, Ouzan D, et al: Compliance with hepatocellular carcinoma surveillance guidelines associated with increased lead-time adjusted survival of patients with compensated viral cirrhosis. Gastroenterology 155 : 431-442, 2018.

4. Boot A, Huang MN, Ng AWT, Ho SC, Lim JQ, Kawakami Y, Chayama K, Teh BT, Nakagawa H and Rozen SG: In-depth characterization of the cisplatin mutational signature in human cell lines and in esophageal and liver tumors. Genome Res 28: 654-665, 2018.

5. Hama N, Totoki Y, Miura F, Tatsuno K, Saito-Adachi M, Nakamura H, Arai Y, Hosoda F, Urushidate T, Ohashi S, et al: Epigenetic landscape influences the liver cancer genome architecture. Nat Commun 9: 1643, 2018.

6. Collino A, Termanini A, Nicoli P, Diaferia G, Polletti S, Recordati C, Castiglioni V, Caruso D, Mitro N, Natoli G and Ghisletti S: Sustained activation of detoxification pathways promotes liver carcinogenesis in response to chronic bile acid-mediated damage. PLoS Genet 14: e1007380, 2018

7. Li G, Liang Y, Sun C, Peng X, Hao N, Liu M, Gao W, Wu H and $\mathrm{He} \mathrm{B}$ : Effective combination therapy of percutaneous ethanol injection and chemotherapy based on injectable low molecular weight gels. Artif Cells Nanomed Biotechnol 9: 1-11, 2018.

8. Chaturvedi M, Schilling J, Beautrait A, Bouvier M, Benovic JL and Shukla AK: Emerging paradigm of intracellular targeting of $\mathrm{G}$ protein-coupled receptors. Trends Biochem Sci 43: 533-546, 2018.

9. Renard D: Cerebral microbleeds: A magnetic resonance imaging review of common and less common causes. Eur J Neurol 25: 441-450, 2018

10. Tan M, Yamaguchi S, Nakamura M and Nagamune T: Real-time monitoring of $\mathrm{pH}$-dependent intracellular trafficking of ovarian cancer $\mathrm{G}$ protein-coupled receptor 1 in living leukocytes. J Biosci Bioeng 126: 363-370, 2018.

11. Bedini A, Baiula M, Vincelli G, Formaggio F, Lombardi S, Caprini M and Spampinato S: Nociceptin/orphanin FQ antagonizes lipopolysaccharide-stimulated proliferation, migration and inflammatory signaling in human glioblastoma U87 cells. Biochem Pharmacol 140: 89-104, 2017.

12. Song X, Zhu S, Xie Y, Liu J, Sun L, Zeng D, Wang P, Ma X, Kroemer G, Bartlett DL, et al: JTC801 Induces pH-dependent death specifically in cancer cells and slows growth of tumors in mice. Gastroenterology 154: 1480-1493, 2018.

13. Zheng CJ, Yang LL, Liu J and Zhong L: JTC-801 exerts anti-proliferative effects in human osteosarcoma cells by inducing apoptosis. J Recept Signal Transduct Res 38: 133-140, 2018.

14. Zhang Y, Simpson-Durand CD and Standifer KM: Nociceptin/orphanin FQ peptide receptor antagonist JTC-801 reverses pain and anxiety symptoms in a rat model of post-traumatic stress disorder. Br J Pharmacol 172: 571-582, 2015.

15. Witkin JM, Statnick MA, Rorick-Kehn LM, Pintar JE, Ansonoff M, Chen Y, Tucker RC and Ciccocioppo R: The biology of Nociceptin/Orphanin FQ (N/OFQ) related to obesity, stress, anxiety, mood, and drug dependence. Pharmacol Ther 141: 283-299, 2014.

16. Li JX, Bi YP, Wang J, Yang X, Tian YF and Sun ZF: JTC-801 inhibits the proliferation and metastasis of ovarian cancer cell SKOV3 through inhibition of the PI3K-AKT signaling pathway. Die Pharmazie 73: 283-287, 2018. 
17. da Silva JA, Biagioni AF, Almada RO, de Freitas RL and Coimbra NC: Panicolytic-like effects caused by substantia nigra pars reticulata pretreatment with low doses of endomorphin-1 and high doses of CTOP or the NOP receptors antagonist JTC-801 in male Rattus norvegicus. Psychopharmacology (Berl.) 234: 3009-3025, 2017.

18. Rybczynska AA, Boersma HH, de Jong S, Gietema JA, Noordzij W, Dierckx RAJO, Elsinga PH and van Waarde A: Avenues to molecular imaging of dying cells: Focus on cancer. Med Res Rev 38: 1713-1768, 2018.

19. Ucker DS and Levine JS: Exploitation of apoptotic regulation in cancer. Front Immunol 9: 241, 2018

20. Jiang C, Ma S, Hu R, Wang X, Li M, Tian F, Jiang W, Zhu L and Bian Z: Effect of CXCR4 on apoptosis in osteosarcoma cells via the PI3K/Akt/NF- $\kappa \beta$ signaling pathway. Cell Physiol Biochem 46: 2250-2260, 2018.

21. Carroll MJ, Fogg KC, Patel HA, Krause HB, Mancha AS Patankar MS, Weisman PS, Barroilhet L and Kreeger PK Alternatively activated macrophages upregulate mesothelial expression of P-selectin to enhance adhesion of ovarian cancer cells. Cancer Res 78: 3560-3573, 2018.
22. De Santis MC, Porporato PE, Martini M and Morandi A: Signaling pathways regulating redox balance in cancer metabolism. Front Oncol 8: 126, 2018.

23. Jondal DA, Thompson SM, Butters KA, Knudsen BE, Anderson JL, Carter RE, Roberts LR, Callstrom MR and Woodrum DA: Heat stress and hepatic laser thermal ablation induce hepatocellular carcinoma growth: Role of PI3K/mTOR/AKT signaling. Radiology 288: 730-738, 2018.

24. Kim EJ, Kang GJ, Kang JI, Boo HJ, Hyun JW, Koh YS, Chang WY, Kim YR, Kwon JM, Maeng YH, et al: Over-activation of AKT signaling leading to 5-Fluorouracil resistance in SNU-C5/5-FU cells. Oncotarget 9: 19911-19928, 2018.

25. Guo Y, Wang F, Li H, Liang H, Li Y, Gao Z and He X: Metformin protects against spinal cord injury by regulating autophagy via the mTOR signaling pathway. Neurochem Res, 2018. [Epub ahead of print].

26. Yamazaki S, Higuchi Y, Ishibashi M, Hashimoto H, Yasunaga M, Matsumura Y, Tsuchihara K, Tsuboi M, Goto K, Ochiai A and Ishii G: Collagen type I induces EGFR-TKI resistance in EGFR-mutated cancer cells via mTOR activation through Akt-independent pathway. Cancer Sci 109: 2063-2073, 2018. 